\title{
CAN MOBILE LEARNING MATURITY BE MEASURED? A PRELIMINARY WORK
}

\author{
Muasaad Alrasheedi and Luiz Fernando Capretz \\ University of Western Ontario \\ Department of Electrical and Computer Engineering \\ London, Ontario, Canada - N6A5B9 \\ \{malrash, lcapretz\}@uwo.ca
}

\begin{abstract}
New mobile platforms, connected seamlessly to the Internet via wireless access have become increasingly more powerful and have found usage in a diverse set of application areas. On such area that has seen exponential growth in the use of mobile devices is the educational sector. Learning facilitated by mobile phones mobile Learning (m-Learning) is increasingly being adopted as an alternative way of imparting education by several institutions. The educational institutions are becoming more open to embracing new learning platforms, which in turn has sparked the interest in developing new assessment frameworks.
\end{abstract}

The increasing popularity of $m$-Learning in universities necessitates the development of a process maturity evaluation methodology that would help in successful adoption of the new learning platform within universities. Accordingly, this paper presents a maturity model for evaluating the maturity of universities while adopting the $m$-Learning platform. This is a preliminary framework based on the current understanding of the issue. Later versions are expected to be more detailed and robust with the availability of empirical data from users.

Additionally, there is also is a lack of comprehensive assessment and evaluation methodology for m-Learning platform, which is considered to be one of the major roadblocks in implementing the technology. The present paper addresses an important question: Can m-Learning maturity be measured? One viable solution for the question is adapting the Capability Maturity Model (CMM) framework to design and propose a capability maturity model suitable for m-Learning within educational institutions.

Keywords: Mobile Learning, M-Learning, M-Education, and Capability Maturity Model (CMM).

\section{INTRODUCTION}

Mobile devices have become ubiquitous in the present day world because of their versatility and hence capability to be used in several different ways. The use of devices like mobile phones and more recently tablet computers, have found their way into the educational sector as well. Learners and educators around the world are increasingly using the mobile technology to access information, streamline administration and facilitate learning in new and innovative ways [1]. Many years ago senior executives in a company brought personally owned mobile devices to work and requested the office IT department to support it, giving birth to the Bring Your Own Device (BYOD) trend [2]. The practice is now gaining traction even in the area of education with universities like University of South Florida embracing the movement and providing access to fast wireless network for the use of such devices on campus [3].

Mobile leaning or m-Learning is a learning platform that provides learners 'anytime-anywhere access to educational and university resources. Learners find themselves empowered by using mobile technology to gain access to the required course materials even when they are disconnected from the network [4]. Because of the immense advantages of mobile learning, not to mention the enormous untapped market comprising of most of the universities of the world, the area of mLearning is also seen as an extremely lucrative business opportunity. The global market for m-Learning related products reached $\$ 3.2$ billion in 2010 , additionally, the market growth, measured in terms of the five-year compound annual growth rate (CAGR), is pegged at $22.7 \%$, based on which the revenue in the year 2015 is estimated to reach $\$ 9.1$ billion [5]. The adoption of $\mathrm{m}$ Learning technology offers advantages to both learners and educational institutions involved. On the part of learners, more students will be able to gain access to education, while for educational institutional there will be a definite reduction in the set-up and operational costs [6]. One of the objectives of this paper is to address the benefits that educational institutions will get at various stages of their adopting the m-Learning platform for imparting education.

However, the adoption rate of m-Learning by educational institutions is still slow, which means that despite the many advantages of the platform, there are 
definite barriers for its acceptance within the educational sector. The most pertinent challenge to the acceptance of the m-Learning technology is attributed to the insufficient evaluation of the implementation process of nonexperimental m-Learning platforms [7]. The rapid changes in the mobile technology and differences in priorities of various educational institutions in terms strategies of m-Learning adoption, are only adding to the challenge [8].

The primary research question addressed in this study is: Can $\mathrm{m}$-Learning maturity be measured for educational sector? It is expected that finding a comprehensive answer to this question would help in developing a detailed roadmap that can be used by educational institutions to guide them to completely and successfully integrate mLearning. Thus it can be said that the short term goal of the research is to simply develop a practical evaluation framework for critically assessing the progress of universities while the long term goal it to help the universities reap the maximum benefits by embracing the $\mathrm{m}$-Learning platform.

Educators within an institutional set up have always been reluctant to adopt new teaching platforms as a mainstream mode to impart education. Educators belonging from a technical background are, if possible, even more disinclined to leave the older way of teaching students [9]. Regardless of the reluctance and unwillingness of the educators to adopt newer technologies, several researches have conclusively demonstrated that certain platform such as E-Learning and $\mathrm{m}$-Learning are not only equal to the traditional learning platforms, they can also be used collaboratively with the traditional methods to enhance learning experience [10].

However, researches in the area have mostly concentrated on proving the superiority of the newer learning platforms, instead of concentrating on finding ways in which the technology can be successfully integrated within an institutional set up. The first step in this direction would be to create a roadmap for success and a corresponding framework to evaluate progress at every milestone [10]. One of the most successful frameworks to assess maturity of an institution is the CMM model that was initially used to evaluate the improvement of organizational processes while implementing a software application in an organization [11]. However, the CMM model has been successfully modified and adapted to assess maturity in varied software application domains like the usability of open source software [12] and software product line engineering maturity [13]. This proves that with appropriate modifications, the CMM model can be adapted to assess the maturity of m-Learning within educational institutions as well, which is the primary goal of this paper.

Even so, the framework used to assess the any software application platform, including m-Learning, should not confine itself to technical \& design aspects but must also include metrics determining ease of adoption and usage for users [14]. In fact, user satisfaction is considered to be one of the critical success factors for the adoption of a software application that can be improved only by having proper methods for its test and measurement [12]. A pertinent point in this context is that success of software product implementation within an organization or an institution is to establish a comprehensive, well-defined and unambiguous relationship between inter-disciplinary strategies within an organization and the specific activities related to software application [12].

The paper is structured as follows: Section II enumerates the research motivations. A review of the relevant literature is presented in Section III. Section IV presents an analysis of the existing e-learning maturity model that has been used as a basis for the design of the current framework. The discussion described in Section V. Section VI presents the conclusion from the study comprising of an analysis \& discussion on the proposed model; and possible directions for future research.

\section{MOTIVATIONS}

As mentioned earlier, mobile technology has developed at an extremely rapid pace, developing several functionalities. This in turn has increased the repertoire of its capabilities making the technology a welcome and even necessary addition in several areas, such as the education sector in our context. The versatility of the technology means that it can support learning in standalone environments as well as in conjunction with the traditional teaching techniques i.e. blended context. This has catapulted the field of $\mathrm{m}$-Learning as the new learning paradigm and the field is now the focus of several research studies [9]. Mobile learning platform has been successfully implemented on a pilot basis in many learning setups such as educational institutions and industry as a new mode of instructing learners [15].

Regardless of the differences in contexts of these studies there has been consistent agreement on the existence of several obstacles to the espousal of $\mathrm{m}$ Learning platform in education. Several researchers attribute the lack of a comprehensive framework for evaluating the m-Learning platform higher education to be the foremost challenge in the area of m-Learning [7]. Further, educational institutions, especially the ones imparting higher education are wary of investing extensively in overhauling the existing system by embedding the mobile platform primarily due to the 
extremely fast rate at which newer devices with better capabilities keep entering the market rendering the older devices obsolete. These are the primary obstacles, from the perspective of educational institutions, to implement m-Learning on a larger scale. However, some universities have taken the initiative and successfully integrated the m-Learning platform with their standard educational policy and practice [16].

The presence of an overall framework using which the process of adoption of m-Learning could be made efficient would definitely enhance the learning outcomes for students. Assessment is essential to mobile learning implementation plans because it identifies the areas where growth is required. Currently the learners are looking towards flexible learning modes that have forced educational institutions to adopt the platform as fast as possible. Hence the need for an evaluation methodology is urgent as never before. However, regardless of the urgency, mobile learning evaluation methodology requires a comprehensive framework that has not yet been explored by researchers [17].

The purpose of the m-Learning evaluation framework discussed here is to aid in developing a comprehensive mLearning maturity model. In the initial stage, the framework is expected to identify the stages of maturity from the perspectives of students, instructors and the institution as a whole. The contribution of this research would be to develop an inclusive strategy to evaluate mLearning in the educational set up. Additionally, it also helps in understanding the process of m-Learning within a university and education sector.

Within this context, the present research specifically aims to modify and adapt the CMM framework to evaluate m-Learning platform in educational institutions. While there are several other evaluation frameworks, CMM offers several advantages in this milieu, as will be discussed later. The research will discuss methods to adapt CMM to evaluate m-Learning and develop the roadmap for its future development. Thus the solution to the research question is limited to evaluating CMM as its applies to m-Learning and precisely define each maturity level. A practical extension of the project would be to develop the theoretical framework into a working platform based on empirical data. However, such an endeavor is beyond the purview of the present research,

\section{LITERATURE REVIEW}

Before attempting to assess the maturity level of mLearning implementation, it is important to understand the concept of m-Learning. The term m-Learning can be simply described as the use of any type of devices using hand-held technology in any form prop, improve and aid and enlarge the reach of teaching and learning [18].
Additionally learners can make use of the mobile technology to aid in their learning endeavors by referencing to or exploring the pertinent information useful at the time or in a specific context [19].

Similar to concepts with a wide radii of usage contexts (such as culture, religion etc.), mobile-learning is also difficult to define. The task is make even more challenging in light of the fact that due to the rapid change in technology, the platform is gaining additional and more sophisticated usage features. Further, while newer versions of mobiles are successfully flooding the market, the older phones are equally popular. As a simplest example, mobile learning platform is not limited to learning supported by mobile devices. Several devices from digital cameras to smartphones and notebook computers can be used [18].

One factor that clearly differentiates E-learning from m-Learning is that the latter is restricted to the use of devices that have mobility features. This demarcation has been clearly underlined by several researchers like ElHussein and Cronje [20] while attempting to provide a concise but exhaustive definition of the term. However, the lack of the single factor of mobility does not make mLearning a simple extension of E-learning with an additional feature. The term mobility is not just a feature, it adds several benefits such as self-paced learning, accessibility to learners in remote areas, learning in addition to regular work with immediate application capability etc. This means that architects responsible for developing m-Learning models cannot modify or adapt an existing e-learning application to an m-learning one. The specifications of m-Learning application must be specific based on the multitude of advantages offered by the platform.

Fig. 1 gives an idea of the various ways in which mLearning can be employed in an educational setting

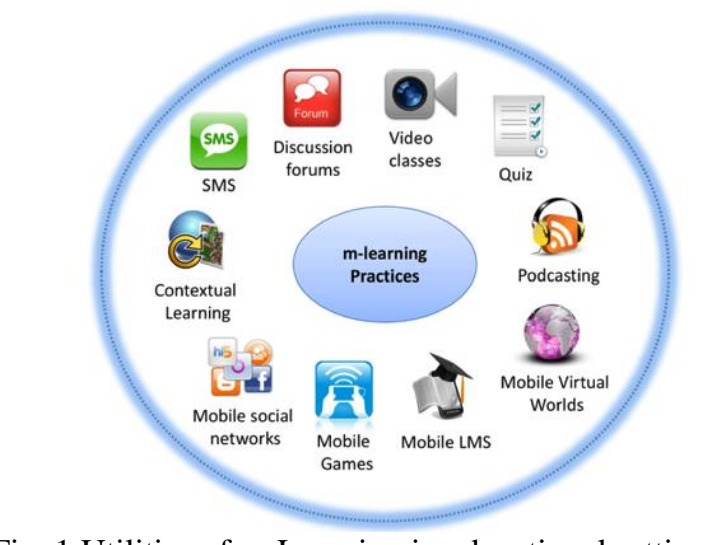

Fig. 1 Utilities of m-Learning in educational setting [21] 


\subsection{Main Components of $m$-Learning}

Ally [16] identified the following to be as the key components of m-Learning:

- The platform can be used learn and train learners, only when it is required. Further as soon as there a need for learning/training is detected the learner can immediately begin.

- Internet can be used as a powerful tool by bother learners and educators to gain access to relevant information as and when required.

- Online learning materials and resources can be accessed as and when there is need

- The principles learnt can be immediately applied in practice and vice versa

- The learning context is limited by the needs of the individual learners. For instance, if a particular course is not required because the learner already known it, it can be skipped.

- Learning is not limited to home or campus or predecided locations. Learners can use their mobile devices even when they are travelling, while working, and even during leisure.

- The previously known concept of online learning is extended to learning from any place or time

- Learners can communicate to fellow colleagues from different background, helping them gain wider perspectives of the world in general.

- Connecting to fellow colleagues can be done regardless of the respective geographical location of each individual.

- People belonging to remote communities can also be a part of the regular learning process of a university

\section{E-LEARNING MATURITY MODEL}

As the name suggests, a maturity model is used to determine how far they can grow or mature with their ability in a particular area. The Capability Maturity Model or CMM is the maturity model for measuring the maturity in the area of software processes. The CMM framework does not restrict it reach to only software and related processes. The reach of the CMM improvement model extends to the entire organization so that the organization reaps full benefits from the induction of a software application. Further, based on the lessons from the present implementation, the organization also puts in a readymade procedure that makes future implementations of similar software applications easier, faster and more efficient. The framework of CMM comprises of five maturity levels as shown in Fig. 2: Initial, Repeatable, Defined, Managed, and Optimizing. Each maturity level is composed of key process areas on which forms the focal point for the organization activities at that particular time [23].

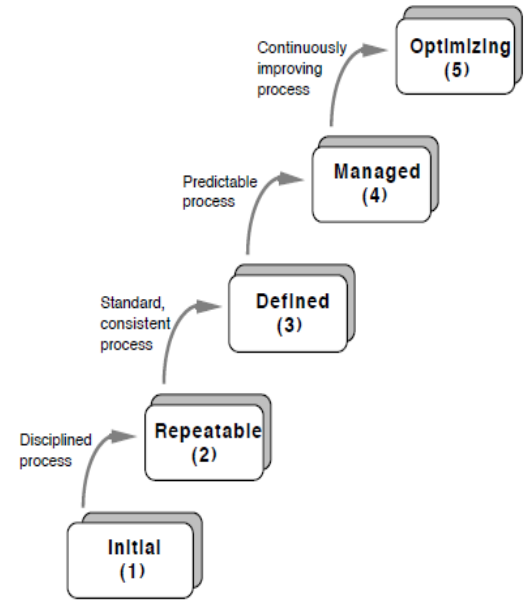

Fig. 2 Five Levels of Capability Maturity Model [17]

Adapting the capability maturity model CMM to evaluate newer platforms in educational sector is not a new idea - not surprising considering that it is the best known and most successful maturity model. An pertinent example of the use of CMM in different application areas is its use in evaluating the E-Learning platform within the university set up [23] Marshall and Mitchell modified CMM to come up with an E-Learning maturity model EMM, where their focus was to boost the adoption of the platform and consequently improve the process $[24,25]$.

The EMM operational goals are similar to the original goal of the CMM model. However, clearly both the maturity models were intended for two very different application areas. A review of the model conclusively negates its usage for the $\mathrm{m}$-Learning platform regardless of the similar domains. This is because the inherent mobility of the technology platform, adds several other usage parameters that are simply not required in case of ELearning platform [26].

In light of the widespread expansion of the Internet, it is difficult to imagine any respectable present day institution not giving access to online libraries for their students or not having a administrative website for learners and educators alike. In fact the better reputation a university has, the better seems to be the quality and functionality of its e-Learning platform [23].

However, there is a clear reluctance in extending the acceptance of new technology to an m-Learning platform. One obvious reason is the rapid change in technology, but this clearly is just one of the many barriers. Hence, it cannot be taken for granted that merely because eLearning succeeded $\mathrm{m}$-Learning adoption will follow the same curve [9]. Further, the implementation methodology would have to be tailored to individual institutions by 
taking into account several factors. Studies have shown that sensitivity to such factors ensures a more efficient and faster adoption of m-Learning technology in educational institutions [27]. It must also be understood that much of the obstacles to the m-learning implementation lie in the failure to select the appropriate software package and other usage issues [10].

E-learning maturity models are fairly developed considering the success of the technology platform. However, even in this case most of the maturity models merely define the roadmap and create clear improvements at each stage. However, the maturity process is not quantified and there is not much evidence of the use of auto-evaluation looks, like seen in CMM-type models. For rectify this, Zhou [28] suggested the e-Learning Process Capability Maturity Model ePCMM. Further, the E-learning maturity framework is extremely unsuitable for direct application for assessing the maturity of m-Learning platform, even though both share the same application area the educational sector.

\section{DISCUSSION}

The primary objective of the present research is to highlight the possibility of developing a maturity model, which is flexible as well as offers the users a guiding framework for enhancing the process of m-Learning. From the literature review conducted in the previous sections, it was found that such a model could be developed on the lines of the existing capability maturity models (CMM). The authors have published a research paper [29] as an initial maturity model for m-Learning.

The maturity model is used to assess whether an institution is capable of establishing and sustaining efficient collaboration of a new learning platform, in this case m-Learning by providing adequate support in both direct and indirect ways. The idea is to first assess the current level of capability and grade it on the maturity scale. Following this the key requirements subsequent higher maturity level are adapted for the current institution in order to suggest changes that will increase the maturity of the institution in terms of adopting a new learning platform successfully. The procedure given in [30] can be taken on as a blueprint for the development of a framework for assessment of m-Learning within an institution.

The first and most important step is to correctly identify the critical success factors for the adoption of technology. This can be done using exhaustive survey and conducting a critical review of the responses in terms of similar studies conducted in the same or related areas. The next step is to device a method for measuring the critical success factors precisely. Once this is done, the initial framework is ready for application and needs a method to use it practically. This is done by developing the procedure for formal assessments and creating forms and procedural documents to assess and retain results in a standard format [30]. Following the procedure will not only ensure that the framework has been developed after thorough research but will also make sure that the assessment based on this framework is carried out methodically with standard storage of results to get the best possible performance.

\section{CONCLUSION}

The educational institutions in present times must realistically accept that mobile phones with their ubiquitous reach will find their way into their milieu as well, sooner rather than later. The faster they are prepared to accept the technology the easier will be its implementation. Within this context, the present study presents a detailed roadmap with defined milestones to successfully implement m-Learning by providing a maturity evaluation framework. This research is an initial stage and a part of new research comprehensive study at the University of Western Ontario we are trying to building an evaluation model and maturity model for $\mathrm{m}$ Learning to evaluate and rating the university in term of adoption for m-Learning platform, by driving the concept of CMM and mapping it to the m-Learning context

To achieve this aim, a detailed research of the existing research in the area of $m$-Learning within the educational set up was conducted as part of the literature review. This helped in understanding the challenges and obstacles to its adoption as well as the perceived benefits by the users. Based on this theoretical background, the m-Learning maturity model will be developed (under progress) that would aid in addressing the challenges to provide the institutions with a clear path to success with defined goals and achievable milestones.

The paper suggests using CMM as a basic model that can be adapted and used to quantitatively appraise the maturity level of an institution adopting mobile technology. The end users of the m-Learning platforms are both learners and educators so the maturity model should incorporate the increased satisfaction levels of both these users to come up with a precise methodology of evaluation. The model developed does require the addition of several features and is not an exhaustive representation; however, even at this preliminary stage the need for such a framework and the advantages of the present framework is easily seen.

\section{Acknowledgements}

The first author would like to thank the Ministry of Higher Education in Saudi Arabia for his scholarship. 


\section{References}

[1] UNESCO, Policy Guidelines for Mobile Learning, 2011.

[2] Osterman Research Inc. (2012, June). Putting Back IT in Control of BYOD, An Osterman Research White Paper [Online]. http://resources.idgenterprise.com/original/AST0066579_Accellion_Osterman_Putting_IT_Back_in_Cont rol_of_BYOD.pdf

[3] Cisco. (2012). University Embraces Bring-Your-OwnDevice with Wireless Network [Online]. http://www.cisco.com/en/US/prod/collateral/wireless/C36698193-00_University_Embraces_Bring-Your-OwnDevice.pdf

[4] ISO/IEC, Information Technology for Learning Education and Training - Nomadicity and Mobile Technologies, Part 2: Learning Information for Mobile Learning, ISO/IES TS 29140-2, 2011.

[5] S.S. Adkins/ (2012, September). The Worldwide Market for Mobile Learning Products and Services: 2010-2015 Forecast and Analysis [Online]. http://www.ambientinsight.com/Resources/Documents/A mbient-Insight-2010-2015-Worldwide-Mobile-LearningMarket-Forecast-Executive-Overview.pdf

[6] J. Hoffmann and N. Miner, Tailored Learning: Designing the Bled that Fits, Massachusetts: American Society for Training and Development, 2009, pp. 182.

[7] J. Wishart and D. Green. (2010, June 29). Identifying Emerging Issues in Mobile Learning in Higher and Further Education [Online]. http://www.jiscdigitalmedia.ac.uk/blog/entry/resourcesfor-mobile-learning

[8] T. Elias, "Universal Instructional Design Principles for Mlearning", International Review of Research in Open and Distance Learning, Canada: Athabasca University, vol. 12, no. 2, 14 pp., 2011.

[9] G. Engel, R. Palloff, and K. Pratt, "Using Mobile Technology to Empower Student Learning", in 27th Annual Conference on Distance Teaching and Learning, University of Wisconsin, 2011, pp. 1-4.

[10] ISO/IEC, Software Process Assessment, Technical Report TR 15504, ISOSPICE, 1998.

[11] M. Kajko-Mattsson, S. Forssander, U. Olsson, "Corrective Maintenance Maturity Model (CM3): Maintainer's Education and Training", in Proc. 23rd International Conf. Software Engineering, IEEE Press, 2001, pp. 610619.

[12] A. Raza, L.F. Capretz, and F. Ahmed, "An Open Source Usability Maturity Model (OS-UMM)", Computers in Human Behavior, Elsevier, vol. 28, Issue 4, 2012, pp. 1109-1121.

[13] F. Ahmed and L.F. Capretz, "An Organizational Maturity Model of Software Product Line Engineering", Software Quality Journal, Springer, vol. 18, Issue 2, 2010, pp. 195225.

[14] A. Ali, A. Ouda, and L.F. Capretz, "A Conceptual Framework for Measuring the Quality Aspect of Mobile Learning", Bulletin of the IEEE Technical Committee on Learning Technologies, IEEE Press, vol. 14, no. 4, 2012, pp. 31-34.

[15] C. Schofield, T. West, and E. Taylor. (2011, November) "Going Mobile in Executive Education - How Mobile Technologies are changing the Executive Landscape?", in
Research for UNICON [Online]. http://www.ashridge.org.uk/Website/IC.nsf/wFARATT/G oing\%20mobile\%20in\%20Executive\%20Education/\$File/ GoingMobileInExecutiveEducation.pdf

[16] M. Ally and A. Palalas. (2011, June) State of Mobile Learning in Canada and Future Directions [Online] http://www.rogersbizresources.com/files/308/Mobile_Lear ning_in_Canada_Final_Report_EN.pdf

[17] C. Paulk, B. Curtis, M. B. Chrissis, and C.V. Weber, "Capability maturity model version 1.1", IEEE Software, vol. 10, no. 4, 1993, pp. 18-27.

[18] MoLeNET. (2011). Learning and skills council (UK) [Online] http://www.molenet.org.uk/ .

[19] Float. (2011). Float mobile learning [Online]. http://floatlearning.com/about/

[20] M.o.M. El-Hussein and J.C. Cronje "Defining mobile learning in the higher education landscape", Educational Technology \& Society, 1vol. 3, no. 3, 2010, pp. 12-21.

[21] J.B. Ferreira, A.Z. Klein, A. Freitas, and E. Schlemmer, Mobile Learning: Definition, Uses and Challenges. Cutting-edge Technologies in Higher Education, vol. 6, 2013, pp. 47-82.

[22] N. Pascoe, Reliability Technology: Principles and Practice of Failure Prevention in Electronic Systems, New Jersey: John Wiley \& Sons, 2011

[23] S. Marshall and G. Mitchell, "An e-Learning Maturity Model" in 19th Annual Conference of the Australian Society for Computers in Learning in Tertiary Education, 2002.

[24] S. Marshall and G. Mitchell, "Potential indicators of elearning process capability" in Proceedings of EDUCAUSE in Australasia, Adelaide, Australia, 2003, pp. $1-8$.

[25] S. Marshall and G. Mitchell, "Applying SPICE to elearning: an e-learning maturity model?," In Proceedings of the Sixth Australasian Conference on Computing Education, Australian Computer Society, Inc,, vol. 30, pp. 185-191., 2004.

[26] C. Neuhauser, "A Maturity Model: Does it Provide a Path for Online Course Design?", The Journal of Interactive Online Learning, vol. 3, no. 1, 2004.

[27] D. Frohberg, C. Coth, and G. Schwabe, "Mobile Learning Projects - A Critical Analysis of the State of the Art", Journal of Computer assisted Learning, vol. 25, 2009, pp. 307-331.

[28] Y. Zhou, "Towards Capability Maturity Model of eLearning Process" Intelligent Information Management, vol. 4, no. 4, 2012, pp. 95-98.

[29] M. Alrasheedi, and L.F. Capretz, "An M-Learning Maturity Model for the Educational Sector", The Sixth Conference of MIT's Learning International Networks Consortium (LINC), MIT, Cambridge, Massachusetts, USA, June 16th - 19th, 2013, Accepted.

[30] S. Hain and A. Back, "Towards a Maturity Model for ECollaboration - A Design Science Research Approach", in Proc. $44^{\text {th }}$ International Conference on System Sciences, Kauai, Hawaii, 2011. 